\title{
The Legacies of Manufacturing and Factories of Industrialised Construction
}

\author{
Rachel Couper ${ }^{1 *}$, Duncan Maxwell ${ }^{2}$, and Mathew Aitchison ${ }^{3}$ \\ ${ }^{1}$ Post-Doctoral Researcher, Future Building Initiative, Monash University, Australia \\ ${ }^{2}$ Post-Doctoral Researcher, Future Building Initiative, Monash University, Australia \\ ${ }^{3}$ Professor, Future Building Initiative, Monash University, Australia \\ "Corresponding author's e-mail: rachel.couper@monash.edu
}

\begin{abstract}
The term 'industrialised construction' carries the promise of an industry transformed, an industry driven by improved processes and higher quality products. One of the more obvious differences between industrialised construction and traditional construction is the factory. Yet it is often undervalued as a secondary consideration to the seemingly more important factors of speed, efficiency and economic rationalisation. This paper offers a reconsideration of the history of the factory as a critical feature in shaping contemporary sites of production in the construction industry. While the manufacturing mega-factories of today continue to develop at a rapid rate, their composition has been shaped by all three previous industrial revolutions and the current fourth. Drawing on the legacies of mechanisation, mass production and automation, today's factory is informed by ideas of lean and agile production, and the connected factory forecast by Industry 4.0 looks towards the internet, cloud and IoT in visions of the future. By charting the evolution of the preceding three phases of industry in relation to key architectural developments of the factory, this paper reflects upon which aspects of these earlier chapters of manufacturing have affected the implementation of Industry 4.0 in the industrialised construction sector. Research in this area has often asked what the production sites of industrialised construction can learn from contemporary manufacturing, such as the automotive, aerospace or technology industries. By contrast, this paper questions the how the potential requirements of industrialised construction might differ from other forms of manufacturing and how this might in turn inform future sites of production in this sector. This paper speculates that a contemporary industrialised construction industry would be wise to re-evaluate the factory as a space specific to construction, distinct from manufacturing origins, in order to better address the broad range of new, or previously under-considered, industry specific requirements.
\end{abstract}

\section{KEYWORDS}

Factory; Industry 4.0; Industrialised Construction; Manufacturing; Offsite Construction; Prefabrication

\section{INTRODUCTION}

'Industrialised construction' is a term that promises a transformed construction industry, one that is formed from clear and defined processes, higher quality built products, reduced build times and 
cost. Underpinned by the power of industry, the most obvious difference when compared to traditional construction is the role of the factory. The factory is primary to industrialised construction - any version of industrialised building would be moot without it. Yet for all its centrality, the factory is often undervalued. This paper offers a reconsideration of the history of the factory as a critical feature in shaping contemporary sites of production in the construction industry.

A common thread in the increasingly prevalent visions of the future in industrialised construction, is the implications of a manufacturing approach advocated by Industry 4.0, in which the potential of the cloud computing, advanced technology and the philosophies of lean and agile production have been maximised. In outlining this future, these visions tend to ask what the production sites of industrialised construction can learn from contemporary manufacturing. By contrast, this paper questions how the developing requirements of industrialised construction differ from other forms of manufacturing and how this might in turn inform future sites of production and the subsequent implementation of Industry 4.0 within the sector. Finally, this paper argues that the composition of modern factories have been shaped not only by current thinking, but also by all three previous industrial revolutions. These include the first industrial revolution at the turn of the 19th century, when mechanisation transformed industry, the second that occurred with the introduction of mass production in the late 19th and early 20th centuries, the third when the rise of automation and technology overhauled production systems and communication during the 20th century, and the current fourth, Industry 4.0.

\section{METHODOLOGY}

This paper approaches the subject through an analysis of the history of the factory in relation to the current requirements of industrialised construction and Industry 4.0. The historical lens of the paper is structured to systematically chart the evolution of the factory across the three previous industrial revolutions and into the current fourth. From this, it is possible to identify the legacies that have shaped the typical composition of the factory and the potential for a re-evaluation of the factory to better address the needs of the construction industry. As will be demonstrated, many such strands persist in mainstream thinking today.

\section{SITES OF PRODUCTION}

One of the recurring problems in the field is what constitutes 'traditional construction'. In this paper, this term describes the complex practices of on-site, in situ construction tailored to each specific project. Industrialised construction, in contrast, refers to a relatively new mode of construction practices that encompass offsite construction, prefabrication and the implementation of advanced technology and/or thinking. Industrialised construction also tends to incorporate new approaches to supply chain and logistics, product platforms, processes and integration. Lessing (2015) defines successful industrialised house building (IHB) as consisting of nine key aspects: planning and control of processes; developed technical systems; offsite manufacture of building parts; long-term relations between participants; logistics integrated into the building process; customer focus; use of information and communication technology; systematic performance measurement and re-use of experience and continuous improvements. These aspects encompass everything from processes to systems, planning, logistics, design-thinking, technology, partnerships, material handling, data collection, skill sets and tacit knowledge, and can (and should) be strategically incorporated into the composition of the factory. This factory composition 
is critical to inform the technical capability of an organisation, the resulting product platform, and determines how the product offering is presented to the market, essentially underpinning the concept of IHB's business model (Brege et al. 2014).

\section{THE ORIGINS OF FACTORY TYPOLOGY Mechanisation}

Historian Joshua B Freeman (2018) believes the factory first made an appearance in England in 1721 when John and Thomas Lombe built the Derby Silk Mill on the River Derwent. Freeman (2018) suggests that it was as if the typology of the factory 'came without infancy.' Setting the precedent for many years to come, the Derby Silk Mill constituted a five-story brick building with a façade punctured by a grid of windows, housing 'a large workforce engaged in co-ordinated production using powered machinery, in this case driven by a twenty-three-foot-high water wheel' (Freeman 2018). A harbinger of the industrial revolution to come, the Derby Silk Mill set in motion the development of a succession of factories across Britain. Predominantly servicing the textile industry, each iteration of the factory increased in scale and mechanization, with several factories housing workforces of well over 1,500 employees by the late 1700s (many of them children).

While smaller-scale operations were still more common, large-scale factories were considered advantageous by wealthy industrialists because they reduced transportation costs by centralising production, afforded greater supervision of quality and workmanship, increased output, reduced the risk of waste and theft and provided owners with the ability to protect royalties, motivations which still exist today. The novelty and notoriety of large-scale factories also afforded the owners a unique status through which they could join (in appearance at least) the British elite (Freeman 2018). Scholar Gillian Darley (2003) refers to this as 'the factory as image' implying that from the outset the factory offered opportunities to shape public perception and a branding of industry. By the early 18th century, this "image" of the factory was so pervasive in Britain, that the leading German architect of the age, Karl Friedrick Schinkel, filled his travel sketchbook not only with the civil, royal and ecclesiastical architecture for which Britain was renown, but will the factories that were spreading out over the landscape around the industrial centres.

By the turn of the century, the increasing scale of factory production and mechanisation powered by steam and water soon created a demand for innovative solutions in building design. The noise, weight and vibrations produced by new loom-machinery restricted the machines to the ground floor and they were therefore often housed in large, single storey sheds adjacent to the multi-storey mills. The objective of lighting these widespan structures led to the development and introduction of the ubiquitous sawtooth roof, an architectural feature still synonymous with the language of industrial architecture up to the present. It was during this period that Jeremy Bentham published designs for the Panopticon after spending time in Russia managing unruly workers. The, now infamous, design incorporated a circular building with a central observation point for maximum surveillance, which Bentham thought perfect for penitentiaries, schools, workhouses and factories. Several entrepreneurs tried variations of the design with little success, though the development highlights the introduction of surveillance in factory production. As innovations such as cast-iron columns and iron-clad wooden beams led to completely iron-framed, and then steel-framed, buildings, the construction of the factory was positioned as a key feature of the industrial revolution, alongside the social upheaval, worker exploitation and pollution that went with it. 
Towards the end of the $19^{\text {th }}$ century textile mills began to be outnumbered by those of the burgeoning steel industry, particularly in the USA. Attempts to control the volatile working conditions and complex nature of the mills saw the development of the theory of scientific management, an approach so closely associated with Frederick Winslow Taylor that it eventually became known as Taylorism. Focused on increasing worker productivity and output, Taylorism sowed the seeds for a shift in manufacturing towards mass production.

\section{Mass Production}

As the twentieth century approached, the typology of the factory building was transformed by a succession of major events including the invention of the combustion engine, the harnessing of electricity, the rapid development of manufacturing in the USA, and ultimately the impact of the two World Wars. Car manufacturer Henry Ford introduced a standardisation of parts (copying techniques of small-arms manufacture) which led to a rational rearrangement of work procedure and the subsequent advent of production-line assembly (this time copied from the meat packing industry). This culminated in the introduction of stationary, task specific work-stations strategically situated around a moving conveyor belt, which radically transformed the factory workplace. First introduced at a large scale in Ford's Highland Park automobile plant in 1913, the work flow of the continuous assembly-line altered architectural designs for factory buildings.

Architect Albert Kahn was at the forefront of this change. His influential design for the Ford Rouge Complex in 1918 comprised of several plants and covered an area of 12,000 acres, offering a capacity for expansion, as well as close proximity to railway transportation and the Rouge River. The success of the venture initiated an international period often referred to in retrospect as Fordism, in which 'system-built factories offered replicable forms and procedures and was highly appropriate to centralised rational planning and central authority' (Darley 2003). The increased efficiency of production revolutionised factory design on an international scale and factories became a symbol of modernity that influenced architects including Le Corbusier, Walter Gropius and members of the Bauhaus (Wilkinson 1991). Kahn went on to design a suite of factories for the automobile and aircraft industries, refining a single-storey format that utilised roof lighting and wide-span steel trusses and slim steel columns to create large open areas capable of accommodating ever-evolving arrangements of production-line assembly.

The Second World War saw the culmination of the development of mass production from the first half of the 20th century. Lessons that had been learned by Henry Ford in the preceding decades were now enacted at an unprecedented scale in response to the global threat. This was especially true in the USA, where aircraft factories prior to 1940 had previously built short-runs of individual planes. The demands of the war saw aircraft production implement a high level of flexibility through innovative multi-line assemblies (Zeitlin 1995). Following the war, mid-century American automotive manufacturers led the world in refined mass production techniques, yet as the $20^{\text {th }}$ century progressed this approach was to be challenged.

\section{Automation}

During the early to mid 1900s both Kiichiro Toyoda and his cousin Eiji Toyoda embarked on several tours of American factories. Both were suitably impressed but observed many ways they thought the system could be improved, particularly in relation to waste. Scholar Ryan Smith 
believes Eiji Toyoda realised that in order to improve the system, they needed to move beyond traditional methods of production and 'take the best of the Fordist mass production and adapt it to achieve high quality, low cost, and flexible outputs' (Smith 2010). Over time, they developed a manufacturing approach that operated in a continuous flow to maximise production efficiency and cater for mass customisation. The approach eventually became known as the Toyota Production System (TPS), which subsequently became known as lean production (Womack et al. 1990).

As they perfected the intricacies of car manufacture, Toyota also ventured into the prefabrication of houses during the 1970s. Their approach centred on five key parameters drawn from lean thinking: Just-In-Time, Jidoka, Heijunka, Standard Work and Keisen (Smith 2010). Each of these held implications for the composition of the factory, effecting the management of stock, material handling and delivery, made-to-order production schedules, transportation systems, the layout of the factory to incorporate a linear sequencing of work stations, combinations of standardised and customised components and the introduction of automation. Essential to automation has been the development and use of computers. The resulting CAD/CAM software digitally drives manufacturing and fabrication machinery, such as CNC machines and robotics. These technological advancements allowed the production line to become increasingly automated, again influencing the composition of the typical factory. As industry focus sharpened towards efficiency and accuracy, robotics began to dominate the production lines of large-scale manufacturing enterprises and rapid advancements in technology altered the way in which manufacturing production is managed, tracked and governed.

\section{Industry 4.0 and the Digital Future}

Today, we are witnessing the fourth phase of the industrial revolution. This evolution seeks to build upon the automation and efficiency gains of the late-20th century by taking advantage of new and emerging technologies made possible by the advent of the internet and new ubiquitous sensing equipment. This contemporary phase was first articulated as 'Industrie 4.0' by the German Federal Government in 2011 (Kagermann et al. 2013). Known as Industry 4.0 in the Anglosphere, the concept imagines a data-focused future of connected and networked factories, or places of production. The internet-driven vision of Industry 4.0 by its nature extends the industrial revolution beyond its traditional physical production location to new virtual realms.

The concept is founded on a blending of the cyber-physical domain as information, people, and objects are connected, and the factory recast as a smart environment (Thoben et al. 2017). This melding of the physical and digital worlds means that Industry 4.0 provides the tools to fundamentally alter the traditional idea of the factory. This reconsideration is possible because of an expanded domain of manufacturing brought about by the concept's supporting concerns, that comprise new business models (Ibarra et al. 2018), new services and products, and an elevated level of control over, and reorganised, manufacturing value chain (Landherr et al. 2016). 
According to Lasi et al. (2014), Industry 4.0 can be summarised by advances observed or new systems hypothesised across seven areas:

1. Smart Factory - an autonomous factory controlled and monitored by sensors

2. Cyber-Physical Systems - a merging of the digital and physical worlds, for example the digital planning and monitoring of the factory to plan new methods as well as machinery maintenance

3. Self-Organisation - decentralised manufacturing locations and decomposed hierarchies

4. Distribution and Procurement - new channels and systems emerge to individually connect elements

5. Product and Services - greater individualisation of product and service design

6. Adaptation to Human Needs - new manufacturing systems to follow human needs

7. Corporate Social Responsibility - a continuation of the 21 st century's increased concern with the environment, social factors, and resource efficiency

Oesterreich and Teuteberg (2016) found three areas of focus within the concept of Industry 4.0 with which the construction industry has a natural synergy. These foci concern the smart factory with its potential for increased material tracking, process monitoring, and automation of production tasks; simulation and modelling where design and production processes and products can be modelled and communicated through virtual and augmented reality, and digitalisation and virtualisation that would see 'big data' inform decision making, cloud-based computing increase efficiency, and social media drive new forms of communication.

\section{DISCUSSION: THE FACTORY OF THE FUTURE}

Tracing the evolution of the factory demonstrates that manufacturing objectives, typically the dominant drivers of factory production, have naturally monopolised the evolution of factory composition and controlled how industrialised, off-site construction is conceived. Mechanisation shaped factory designs to offer reduced transportation costs through centralised production, a marked escalation in output, an increase in the capacity for surveillance and supervision of quality and workmanship, a reduction in waste and the capacity to protect trade secrets. The assembly lines of the eras of Taylorism and Fordism initiated a shift towards mass production, speed and economy, with the factory transforming strategically to enhance workflows and productivity. The rapid growth of the automobile industry, brought about by automation and technology, demonstrated the benefits of strategic factory management in a way that has had lasting impact on perceptions of what factory design should constitute to this day. Co-author of this paper, Mathew Aitchison, has argued for caution in comparing prefabricated housing with car manufacture, citing complexities in industrialised construction that include 'sheer size, parts and compartmentalisation, site conditions, users, climate, codes and regulations, materials and construction, tolerances (or factory vs site), customisation, cost relative to income, supply chain and industry set up' (Aitchison et al. 2018).

Perhaps a more relevant lesson for industrialised construction should be drawn from Darley's argument that Kahn's expertise lay in 'master-planning a complex chain of interconnected processes at a very large scale' (Darley 2003). Darley's argument speaks directly to Lessing's defining features of industrialised construction. The nine aspects identified do not sit distinct and 
separate, but instead must be integrated in order to support and enhance the overall concept. Integration has emerged in recent decades as something of a 'holy grail' for construction, particularly when industrialised. Yet approaches to integration are commonly rooted in process, with little consideration of the site of production or uniqueness of product. Advances beyond Industry 4.0 herald a new domain that is less bound by physical constraints of any previous chapter. For construction, this brings a number of challenges concerning the future of the industry, whilst simultaneously offering a range of new opportunities. Through the introduction of these new approaches industrialised construction will no longer be bound by the physical constraints of individual, centralised factories, instead released into the virtual domain. This shift will not only transform the way buildings are constructed but also the sites in which they are produced.

\section{CONCLUSION}

The construction industry is renowned for its complexity (Winch 2010), has a culture of shortterm thinking brought about by its project-based nature (Dubois and Gadde 2002), and suffers from certain 'peculiarities' (site-based production, temporary organisations, unique products) that mean that it must be considered unique and distinct from manufacturing (Vrijhoef and Koskela 2005). Previous research has sought to critically consider the historic tendency within the construction industry to seek lessons from manufacturing, seeking to implement processes based on mass and lean production, proposing that construction would benefit from a complex systems approach (Winch 2003). Yet this call has until today gone unanswered.

The digital-age that has driven the emergence of Industry 4.0 presents a potential toolkit by which we can reconsider historic modes of production anew, in a way that is uniquely suited to the complexity and peculiarities of construction. This virtual world allows the individual product to be 'prototyped' at radically reduced cost and impact, production processes can be modelled and analysed before being enacted in a new decentralised modes for example by temporary, flying factories, and new business models combined with a focus on long-term relationships and continual improvement brought about by industrialised construction are redefining the construction value chain to progress it beyond its historic temporary and fragmented nature. There remains much work to be done in charting the strands of historical episodes up to the present day, as there also remains, much work to chart how these strands will coalesce in an Industry 4.0 future for Industrialised building, of which this paper is a first instalment.

\section{ACKNOWLEDGEMENTS}

This research was conducted as part of an ongoing CRC-Project funded by industry and the Australian Federal Government that supports industry-led collaboration between industry, researchers and the community.

\section{REFERENCES}

Aitchison, Mathew. (2017). "A House Is Not a Car (Yet)." Journal of Architectural Education 71, no. 1: 10-21.

Aitchison, Mathew et al. (2018). Prefab housing and the future of building: product to process. Lund Humphries, London, UK. 
Brege, Staffan, Lars Stehn, and Tomas Nord. (2017). "Business Models in Industrialized Building of Multi-Storey Houses." Construction Management and Economics 32, no. 1: 208-26. doi:10.1080/01446193.2013.840734.

Darley, Gillian. (2003). Factory. Reaktion, London, UK.

Dubois, Anna, and Lars-Erik Gadde. (2002). "The Construction Industry as a Loosely Coupled System: Implications for Productivity and Innovation." Construction Management and Economics 20, no. 7: 621-31. doi:10.1080/01446190210163543.

Freeman, Joshua Benjamin. (2018). Behemoth: a history of the factory and the making of the modern world. W. W. Norton \& Company, New York, USA.

Ibarra, D., J. Ganzarain, and J. I. Igartua. (2018). "Business Model Innovation Through Industry 4.0: a Review." Procedia Manufacturing 22: 4-10. doi:10.1016/j.promfg.2018.03.002.

Kagermann, H., W. Wahlster, and J. Helbig, eds. (2013). Recommendations for implementing the strategic initiative Industrie 4.0: Final report of the Industrie 4.0 Working Group. Frankfurt, Germany.

Lessing, J. (2015). Industrialised House-Building - Conceptual orientation and strategic perspectives. Doctoral Dissertation, Lund University, Sweden.

Landherr, M., U. Schneider, and T. Bauernhansl. (2016). "The Application Center Industrie 4.0 - Industry-Driven Manufacturing, Research and Development." Procedia CIRP 57: 26-31. doi:10.1016/j.procir.2016.11.006.

Lasi, H., P. Fettke, H. G. Kemper, T. Feld, and M. Hoffmann. "Industry 4.0." (2014). Business \& Information Systems Engineering 6, no. 4: 239-42. doi:10.1007/s11576-014-0424-4.

Oesterreich, T. D., and F. Teuteberg. (2016). "Understanding the Implications of Digitisation and Automation in the Context of Industry 4.0: a Triangulation Approach and Elements of a Research Agenda for the Construction Industry." Computers in Industry 83: 121-39. doi:10.1016/j.compind.2016.09.006.

Smith, Ryan E. (2010). Prefab architecture: a guide to modular design and construction. John Wiley \& Sons, Hoboken N.J, USA.

Thoben K.D., S. Wiesner, and T. Wuest. (2014). "Industrie 4.0" and smart manufacturing-a review of research issues and application examples. International Journal of Automation Technology 11: 4-16.

Vrijhoef, R, and Lauri Koskela. (2005). "Revisiting the Three Peculiarities of Production in Construction." Lean Construction Theory. doi:10.1080/09613210110039266.

Wilkinson, Chris. (1991). Supersheds: the architecture of long-span, large-volume buildings. Butterworth Architecture, Oxford, UK.

Winch, Graham. (2003). "Models of Manufacturing and the Construction Process: the Genesis of Re-Engineering Construction." Building Research \& Information 31, no. 2: 107-18. doi:10.1080/09613210301995.

Winch, G. Governing. (2010). "The project process: a conceptual framework." Construction Management and Economics, 19(8): 799-808.

Womack, James P, Daniel T Jones, and Daniel Roos. (2007). The Machine That Changed the World, Simon and Schuster, New York, NY, USA.

Zeitlin, J., 1995, 'Flexibility and Mass Production at War: Aircraft Manufacture in Britain, the United States, and Germany, 1939-1945' Technology and Culture 36(1), pp. 46-79 